DOI 10.20396/temáticas.v27i54.12343

\title{
AUSÊNCIAS INCORPORADAS
}

\author{
Evandro Cruz Silva'
}

RESUMO: Este texto constitui uma resenha do livro Ausências Incorporadas: uma etnografia entre familiares de mortos e desaparecidos políticos no Brasil, de Desirée Azevedo, publicado em 2018 pela Editora da Unifesp. A resenha tem como objetivo apresentar os pontos principais da obra e apontar para direções críticas possíveis, além de avaliar o impacto que esta constitui no debate acadêmico especializado. Baseado numa etnografia extensa com movimentos de familiares de desaparecidos da Ditadura Militar Brasileira (1964-1985), Azevedo demonstra a relação íntima entre política, laços de parentesco e disputa pela memória.

PALAVRAS-CHAVE: Etnografia; Ditadura Militar Brasileira; Política, Parentesco, Memória.

\section{INCORPORATED ABSENCES}

\begin{abstract}
This article makes a review of the book Ausências Incorporadas: uma etnografia entre familiares de mortos e desaparecidos políticos no Brasil, by Desirée Azevedo, 2018. The review has as a main focus to present the key points from the book and to point out some possible critiques on it, as well to measure his impact on the specialized academic debate. Based on a extend ethnography between social movements that reclaim the rights of families of victims from the brazilian military dictatorship (1964-1985), Azevedo's book shows the intimate relation between politics, kinship ties and the dispute for memory.
\end{abstract}

KEYWORDS: Ethnography; Brazilian Military Dictatorship; Politics, Kinship, Memory.

\footnotetext{
${ }^{1}$ Doutorando em Ciências Sociais pela Universidade Estadual de Campinas, com financiamento da Coordenação de Aperfeiçoamento de Pessoal de Nível Superior - Brasil (CAPES) - Código de Financiamento 001. Contato: cruzsilvaevandro@gmail.com
} 
O livro Ausências Incorporadas: uma etnografia entre familiares de mortos e desaparecidos políticos no Brasil, de Desireé Azevedo (2018), surge como feliz contribuição ao campo de estudos sobre movimentos sociais, e ocupa, ao mesmo tempo, um espaço importante na biografia disputada sobre o último período ditatorial brasileiro (1964-1985). Se, no primeiro caso, Azevedo demonstra através de um preciso trabalho etnográfico a construção constante do sujeito político que militará pelas consequências políticas de tal período, no segundo, o livro age como mais uma peça na disputa sobre a história nacional recente.

No prefácio escrito pela orientadora de doutoramento de Azevedo, Bella Feldman Bianco, a contextualização da obra em um período de crescente polarização ocupa logo as primeiras linhas. Convulsionado por quase meia década de grandes cisões políticas, o país assiste hoje uma disputa intensa por seus principais motes discursivos e por sua memória. Entre os temas que mobilizam os ânimos mais violentos está a memória sobre o significado do período pós-1964 na vida nacional. O livro de Azevedo é uma fina etnografia de umas das lutas pela representação e consequência política desta história. Assim, ao final da leitura de Ausências Incorporadas, aprendemos mais sobre como se dá o cotidiano e as chaves epistemológicas de uma luta que de forma simultânea tenta disputar o passado, mobilizar o presente e construir futuros possíveis para os perseguidos, assassinados e desaparecidos políticos do regime militar, assim como para a própria concepção de história nacional.

Tudo isso é possível devido à grande habilidade de Azevedo enquanto etnógrafa, que é capaz de separar de maneira organizada os argumentos êmicos das discussões teóricas, demonstrando, ao mesmo tempo, como ambas se retroalimentam. Desta forma, a autora apresenta como os dois principais argumentos encontrados em campo - a excepcionalidade das violências da ditadura como forma de diferenciar as opressões de outras naturezas e a naturalidade produzida pela relação de parentesco como forma de justificativa do direito de defesa - se relacionam com discussões consagradas como a relação entre parentesco, militância, política e violência. 
O primeiro capítulo do livro se dedica ao primeiro argumento apresentado. O problema em questão é de como transformar a luta contra a violência de Estado em algo excepcional em um país com uma história repleta de opressões estatais. A resposta a esta questão se dá com a produção da figura dos "mortos e desaparecidos políticos" e de como ela passa pela sua criação enquanto figura excepcional e vítima diferenciada frente as tantas outras vítimas do Estado brasileiro.

Tal construção tem ponto de partida na figura do "desaparecido", produto das técnicas da ditadura de fazer desaparecer o corpo de seus antagonistas para que não houvesse possibilidade de contestação jurídica (afinal, sem corpo, não haveria crime). A figura do "desaparecido" é reapropriada pelo movimento de familiares como maneira de exemplificar a crueldade e a extensão dos horrores do regime militar. Tal processo também serve como forma de demonstração que o período da ditadura estende seus efeitos ao tentar encobrir o verdadeiro paradeiro de suas vítimas. Desta demonstração se baseia a forma discursiva que coloca a continuidade da luta contra a ditadura não mais como uma disputa contra o regime (que já não mais existia), mas sim como uma militância pela Verdade, Memória e Justiça e seus efeitos.

Esta transformação tanto serve como centro de gravitação dos grupos que se produzem a partir da luta quanto cria um instrumento jurídico que se liga diretamente às ocorrências da ditadura e burocratiza em procedimentos judiciais a figura do "desaparecido político". Como veremos mais a frente, o instrumento jurídico e a formação de um campo discursivo que exaltava a excepcionalidade da violência empregada na ditadura se uniria a um trabalho de construção do direito natural dos familiares das vítimas em requerer seus direitos perante o Estado.

O capítulo segundo, denominado "Tudo começou com a luta dos familiares", dá conta da comunidade moral que tomará para si o protagonismo da luta pela produção da memória dos tempos da ditadura a partir da perspectiva de suas vítimas preferenciais. Neste capítulo de sua etnografia, Azevedo demonstra como as peças e campanhas feitas pelo Grupo Tortura Nunca Mais e pela Comissão de Familiares apostam nos laços de parentesco como forma de produção da legitimidade. 
A construção da militância em relação a ditadura é trazida assim nos dois primeiros capítulos do livro a partir de um par complementar: a violência excepcional da ditadura produz vítimas excepcionais (vítimas políticas) e seus familiares têm, por direito natural, legitimidade para reclamar verdade, memória e justiça. Se estas são as bases pelas quais o movimento de militância se consolida, nos passos seguintes do argumento a autora demonstra como tais bases se reproduzem na operação cotidiana a partir da produção de casos que reiteram suas causas e de uma relação instável com o Estado que é, ao mesmo tempo, algoz, provedor e devedor central de suas bandeiras.

No terceiro capítulo, intitulado "Nossos Mortos e Desaparecidos", Azevedo descreve a maneira como, dentro dos processos inaugurados pelas Comissões da Verdade, os movimentos de militância dos familiares das vítimas da ditadura operacionalizam suas pautas. Tal operação se divide em dois momentos específicos. A primeira é uma reafirmação do antagonismo entre militância de esquerda e Estado ditatorial que diferenciaria as mortes e desaparecimentos de seus parentes das demais. A segunda é a replicação desta ideia a partir da reunião de casos exemplares que vitimaram seus familiares.

Esta reafirmação da militância como causa da violência sofrida por seus entes queridos leva à produção de uma fronteira entre as vítimas que são "políticas" e aquelas que não são. Tais fronteiras, contudo, estão longe de comportar claras delimitações. Em um exemplo desta dinâmica, Azevedo descreve como um dos sujeitos apresentados como caso de "desaparecimento político" frente a Comissão tinha sua militância conhecida por pouquíssimas pessoas. Em outro, a autora relata o encontro com um familiar de uma das vítimas encontradas no Cemitério de PerusSP que argumentava que seu parente havia morrido "por ser de esquerda", mas que preferiu não trabalhar pela construção desta memória, o que resultou no seu desaparecimento dos registros principais de vítimas da ditadura. Assim, se no primeiro caso a produção de uma figura militante parecia condição necessária para entrada do sujeito no hall de vítimas a serem defendidas na Comissão, no outro, podemos entender como o esforço de familiares em produzir a figura de militância após a vitimização 
é tão importante quanto a própria participação do sujeito em atividades políticas de esquerda durante a ditadura.

$\mathrm{O}$ antagonismo entre militância de esquerda e Estado ditatorial que produz as fronteiras das vítimas políticas e vítimas comuns também cria reverberações na própria relação entre o movimento de familiares e as instâncias estatais. No capítulo quarto, denominado "Nós Não Somos Estado" a etnografia mostra o caminho difuso da relação do movimento com o governo: o mesmo Estado que é representado como algoz no passado é o que também centraliza as energias de cobrança e é principal fonte de recursos do movimento atualmente.

Tal argumento demonstra como o movimento depende da centralidade do Estado em duas vias distintas e complementares: é necessário produzir um Estado algoz, simbolicamente antagônico e juridicamente imputável e, ao mesmo passo, criar relações com as formas estatais e suas burocracias para que seja possível operacionalizar as reparações históricas reclamadas. A forma como esta dupla operação se desenrola é demonstrada a partir do processo jurídico que coloca o Estado Brasileiro na condição de réu da Corte Interamericana de Direitos Humanos pelos atos da ditadura e da relação tensa que os militantes que integram comissões de direitos humanos criadas pelos governos federais e estaduais vivem para separar suas atividades das outras burocracias estatais.

As fronteiras difusas entre militância e não militância e a relação antagônica que ao mesmo tempo projeta o Estado como algoz e provedor cria os contornos de uma luta política em seus mais finos detalhes e contradições, resultado usual de uma etnografia feita com esmero e precisão. Ainda fruto de seu trabalho de campo com os familiares e de uma redação robusta, Azevedo traz no quinto capítulo, bem como nos apontamentos finais, as histórias de seus interlocutores e interlocutoras na sua busca em transformar as dores vividas em família numa pauta de mobilização pública.

Por meio das histórias daqueles e daquelas que lutam cotidianamente pela memória de suas famílias e de um momento político da vida nacional, a autora termina sua etnografia num tom sensível, ao destacar a constante capacidade das lutas dos familiares de mortos e desaparecidos pela ditadura 
em transformar a vulnerabilidade derivada da desestruturação familiar em energia de luta e resistência no espaço público.

Por fim, dois apontamentos podem ser feitos como contrapontos aos argumentos apresentados ao percorrer do texto. Ao se debruçar sobre dois temas de ampla disputa em território nacional - as legitimidades do que pode ser enquadrado enquanto violência de Estado e as disputas pela memória da Ditadura Militar Brasileira -, os argumentos trazidos a partir da etnografia de Azevedo, convida-nos a expandir o escopo de suas discussões.

O primeiro apontamento diz respeito à construção da legitimidade do campo moral de militância através da naturalidade dos laços de parentesco. Como bem demonstrado durante a etnografia de Azevedo, a referência ao campo moral familiar se tornou parte fundamental da construção do movimento, aparecendo em cartazes, campanhas e discursos sucessivos. Contudo, apesar de válida para o objeto proposto, é importante lembrar que a relação entre o "sujeito vítima" de violência de Estado e seus familiares nem sempre resultam na legitimidade do último em reclamar os direitos dos primeiros.

Estudos que descrevem a mesma relação quando em âmbitos familiares de vítimas periféricas apontam que a naturalidade do laço de parentesco habita um âmbito mais difuso. Esta ligação permite que a situação transite entre legitimação dos parentes na luta pelo direito das vítimas e a criminalização de famílias inteiras, ambas tendo como argumento a mesma ligação de naturalidade do sujeito criminalizado e seus entes afetivos (cf. por ex., FARIAS, 2014; SANJURJO \& FELTRAN 2015; VIANNA, 2013).

O segundo apontamento diz respeito à construção do período ditatorial e suas violências como um momento excepcional da vida política brasileira. Esta separação entre violências excepcionais e cotidianas parece ter o momento da Ditadura Militar e suas respostas posteriores os momentos de maior emergência. Se na década de 1960 as pautas da segurança pública (ligada à proteção patrimonial contra a suposta violência urbana) e a da segurança nacional (relacionada à proteção nacional contra a suposta ameaça de esquerda) andavam juntas e com fronteiras difusas, é evidente que o final da ditadura vai eleger a segunda como excepcional e 
intolerável enquanto a primeira entrará no campo das medidas inevitáveis para a manutenção da democracia (cf. MARQUES, 2018).

Estes dois pontos levantados servem para retificar a importância do livro de Azevedo para os debates que tratam tanto da construção da memória sobre a ditadura quanto das possibilidades de reação frente as violências produzidas pelo Estado. Assim, produto de uma etnografia precisa com familiares de mortos e desparecidos da ditadura militar e de uma escrita clara e organizada com debates teóricos bem localizados, o livro Ausências Incorporadas é uma contribuição importante para as discussões acadêmicas das mais complexas, e, ao mesmo tempo, trata-se de um documento de uma história que está longe de encerrar as disputas sobre sua memória.

\section{REFERÊNCIAS BIBLIOGRÁFICAS}

AZEVEDO, Desirée. Ausências Incorporadas: uma etnografia entre familiares de mortos e desaparecidos políticos no Brasil. São Paulo: Editora Unifesp, 2018.

FARIAS, Juliana. Governo de Mortes: Uma etnografia da gestão de populações de favelas no Rio de Janeiro. Tese de Doutorado em Sociologia e Antropologia, Universidade Federal do Rio de Janeiro, 2014.

MARQUES, Adalton. Humaniz̧ar e Expandir: uma genealogia da segurança pública em São Paulo. São Paulo: IBCCrim, 2018.

SANJURJO, Liliana; FELTRAN, Gabriel. "Sobre lutos e lutas: violência de estado, humanidade e morte em dois contextos etnográficos". Ciência e Cultura, v. 67, n. 2, pp. 40-45, 2015. Disponível em:<http:// cienciaecultura.bvs.br/scielo.php?script=sci_arttext\&pid=S000967252015000200013\&lng=pt\&tlng=pt $>$.

VIANNA, Adriana. O fazer e o desfazer dos direitos: experiências etnográficas sobre políticas, administração e moralidades. Rio de Janeiro: E-Papers, 2013.

Texto recebido em 16/05/2019 e aprovado em 26/08/2019 
